\title{
Suture suspension brow-lifting: The Minitac system
}

\author{
James D. Frame, Bassem M. Mossaad \\ Post-Graduate Medical Institute, Anglia Ruskin University, Chelmsford, Essex CM1 1SQ
}

Email address:

j.frame@btinternet.com (J. D. Frame)

\section{To cite this article:}

James D. Frame, Bassem M. Mossaad. Suture Suspension Brow-Lifting: The Minitac System. Journal of Surgery. Vol. 2, No. 6, 2014, pp. 93-97. doi: 10.11648/j.js.20140206.13

\begin{abstract}
As their face ages, a significant number of individuals require elevation of the eyebrows to improve brow-ptosis and pseudo-ptosis of the upper eyelids. This may be for functional disability, i.e. when there is a reduction in visual fields, or for purely cosmetic reasons. Eyebrow elevation can be achieved by non-surgical or by direct surgical methods. There are advantages and disadvantages to the non-surgical use of Botulinum Toxin or fillers, and minimally invasive techniques such as endoscopic methods or Endotine ${ }^{\circledR}$ fixation. Bicoronal brow lift procedures appear to be reducing in popularity compared to the other methods. Suture suspension of the brow is not new but recently Minitac $®$, a kit system that allows intra-osseous fixation using two non-absorbable paired needle sutures, has been introduced. Whilst this system was primarily developed for ligament to bone approximation, we demonstrated in this mini-series that it can be adapted to provide a simple and effective means for brow lifting, whilst controlling the vectors of elevation. Due care and the understanding of anatomy are essential.
\end{abstract}

Keywords: Browlift, Minitac ${ }^{\circledR}$, Ptosis

\section{Introduction}

In the context of the ageing face, the forehead is often overlooked during the aesthetic assessment, particularly if the forehead is covered with a fringe. Horizontal and glabella frown lines can be adequately "controlled" with Botulinum Toxin (1) but many patients are not comfortable with the lack of forehead expression, the frequency of injection treatments required and the development of pseudo-ptosis of the brow from excessive treatment. Elevation of the eyebrows though is also possible using Botulinum Toxin and indeed "fillers" to the brow and infra-temporal fossae. Surgical brow-lifting is via open or closed methods (2). Open techniques involve either direct excision and suture suspension of tissue above the brow, or a more distant elevation via a bicoronal approach. The advantages of the former include the use of local anaesthetic and simplicity but the disadvantage is an obvious scar above the eye brow and an inevitable fullness of the tissue (3). The advantages of a bicoronal approach are excellent access and the ability to trim the frontalis muscles. The disadvantages can include extensive scar, hair loss, numbness and also the risks with a general anaesthetic $(2,4)$. "Closed" brow-lift includes minimally invasive techniques such as Endoscopic Forehead Lift, Endotine ${ }^{\circledR}$ lift and simple suture suspension. Endoscopic methods involve the availability of expensive equipment and expertise and results in the ageing patients are often disappointing unless a suspensory procedure is included (5). Endotine ${ }^{\circledR}$ forehead lifts do not really elevate the lateral brow if applied within the forehead hairline but they do inhibit forehead descent and block the progress to brow ptosis (6). Endotines ${ }^{\circledR}$ inserted at brow level are easily palpable but can be useful when used to elevate the brow via an upper blepharoplasty approach.

Suture suspension techniques are not new (7) and do involve long "hitch-up" sutures extending from the forehead hairline down to the brow (8), and their permanent fixation onto and into the skull (9). This fixation is usually with screws (10). Medial and lateral brow suspension may require two separate sutures and screws and can be very effective and simple to carry out. The disadvantages are that the suture may be easily palpable, particularly in patients with poor soft tissue cover, and if the elevation is too great static forehead lines can develop which may require a combined forehead or Endotine ${ }^{\circledR}$ lift to soften the appearance.

Recently Smith \& Nephew has distributed the Minitac $₫$ System. This is a single screw suture fixation device primarily designed to deliver a headless cortical screw into bone and leave a pair of $2 / 0$ Ultrabraid ${ }^{\circledR}$ sutures (with tapered needles) available for the reconstruction of tendon or ligaments. A guarded drill is also contained within the kit and this is essential to allow for the introduction of the cortical screw into hard cortical bone. Smith \& Nephew also provide a loop wire 
suture retrieval device. The Minitac ${ }^{\circledR}$ System has been successfully used in brow-lifting in five patients.

\section{Patients and Methods}

Five fully informed adult patients consented to the use of the Minitac ${ }^{\circledR}$ in brow suspension. The procedure was performed as a single procedure or combined with either upper eyelid blepharoplasty and/or a face-lift. A general anaesthetic was used in all patients. At surgery the patient was put in an elevated supine position with head elevation. The face, forehead and scalp were washed with topical antiseptic and draped for surgery with exposure of the forehead, 2 inches of adjacent scalp and complete exposure of the face. Two small skin incisions approximately $1 \mathrm{~cm}$ in length in the sagittal plane were made either side of the midline in the scalp, in the line of the pupil. These incisions continue down to cortical bone and a blunt instrument inserted in the supraperiosteal plane to easily elevate the skin and frontalis forehead tissue via a relatively bloodless field.

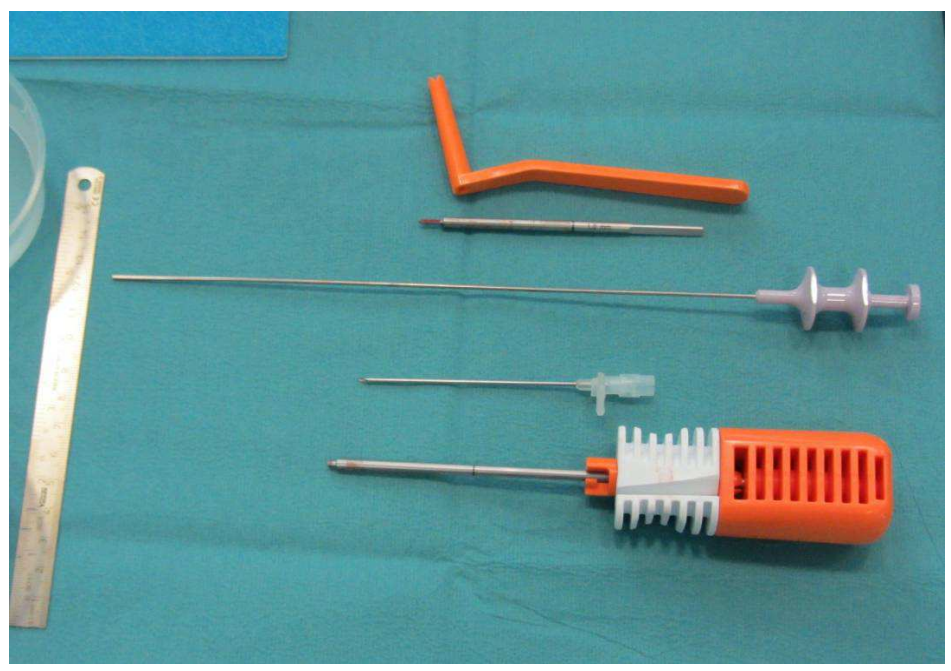

Figure 1. Minitac ${ }^{\circledR}$ Kit (Smith \& Nephew).

The Minitac $®$ drill and guard (Fig 1) were used to drill through the outer table of skull via retracted skin edges and the Minitac ${ }^{\circledR}$ screws were tightened into the drill hole according to the instructions. The paired sutures were released from the screwing device and the anchorage of the subcortical screw checked by exerting a reasonable traction force. The drill length may be too long for the skull so the guard must be used to block the drill from overly deep penetration. Care must be taken to avoid drilling through the inner table of the skull. The sutures and needles are removed from the kit and the paired sutures are identified via their different appearance (one paired suture has longitudinal stripes). All needles are removed from the sutures.

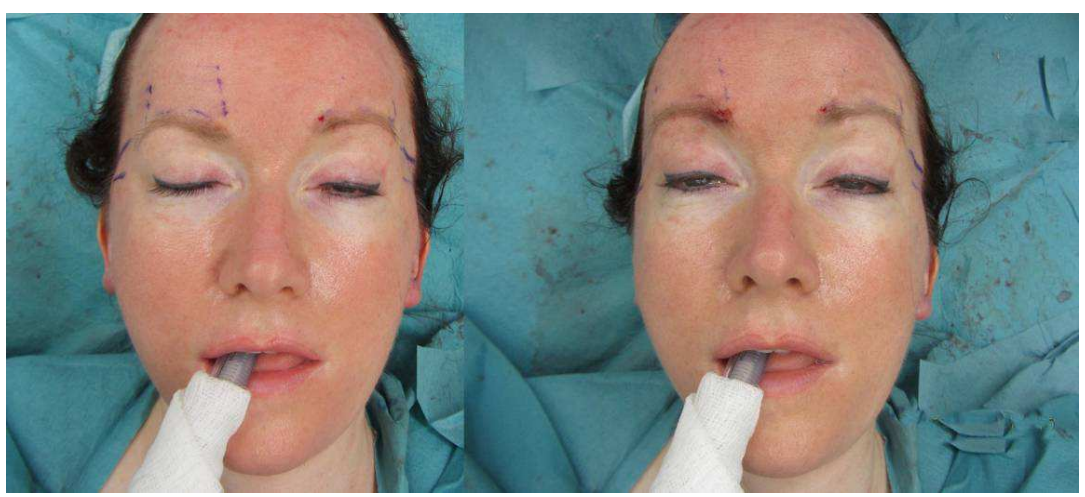

Figure 2. (Left) Left brow lift done, the vectors for the right brow lift are shown. (Right) Right brow lift done, symmetry achieved.

Two small punctures are made in the appropriate areas of the medial and lateral brow with a size 14 Venflon needle and a long loop suture retriever is passed from the scalp wound to one of the brow punctures, taking a $2 / 0$ Ultrabraid ${ }^{\circ}$ suture within the loop from the incision to emerge from the brow puncture site. The retriever is then reinserted carrying the suture back through the brow puncture up to the scalp incision. A small anchoring "bite" of soft tissue at the brow level is essential to permit the elevation but the suture must be buried deep to the subcutis at this point to prevent exposure of suture. The second suture is used in similar fashion to hitch up the opposite end of the brow. Once both sutures have been applied to both brows the elevating sutures are tied at the scalp level with controlled tension to provide the desired vector of pull and symmetry (Fig 2). Minor puckering above the brow may occur at the point of excessive lifting. The suture tie can be 
released slightly to control this. Major puckering can be easily achieved by excessive tightening of the suture knot but must be avoided. The small wounds in the scalp are either stapled or sutured. A firm wool dressing and bandage are applied to the forehead. The whole process takes about forty-five minutes or less.
Five patients underwent symmetrical brow lift using the Minitac ${ }^{\circledR}$ system in 2012. All patients have been reviewed at follow up and photographed and only two patients gave consent for release of photographs. All patients had a satisfactory outcome with a stable and elevated position of eyebrows and there were no major complications reported.

\section{Results}

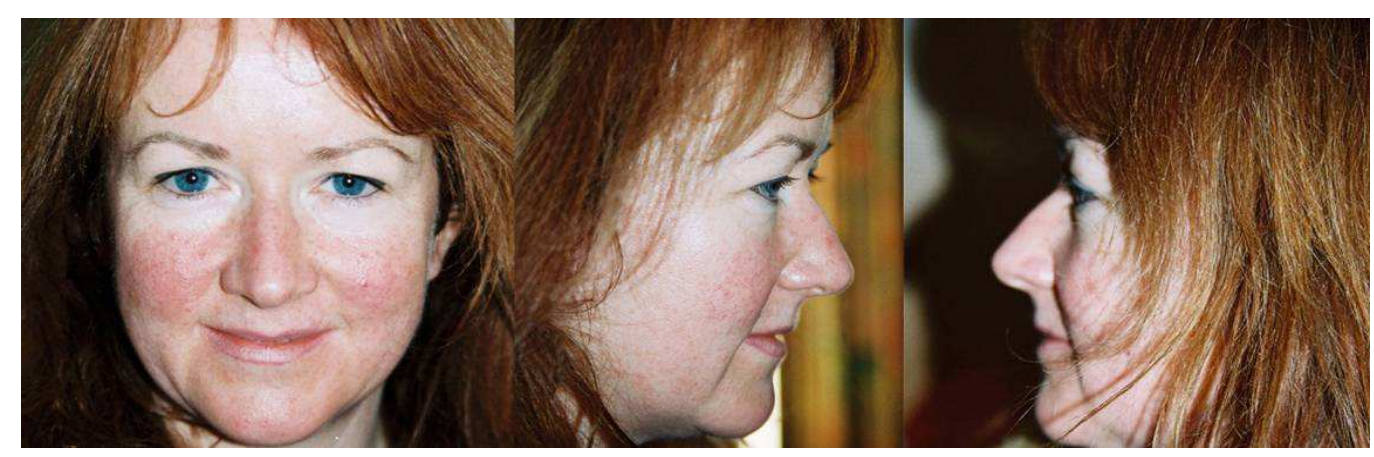

Figure 3. Preoperative photos showing pseudoptosis of the eyelid and arched brow ptosis with mild asymmetry.

FW is a 49 year old lady who typifies the type of patient who would benefit from this technique (Fig. 3). A previously successful facelift and upper blepharoplasty had highlighted a mild degree of brow ptosis that she wanted improved. Minitac $₫$ brow elevation was performed in May 2012 and the results are shown at ten weeks post procedure (Fig. 4). There is a small palpable nodule, not visible, in the medial aspect of the left eyebrow and by careful palpation the suspension suture can be felt sitting on periosteum. They are neither obvious nor of concern to the patient who remains delighted with the outcome one year later.

RH is a seventy year old lady with heavy lines and brow ptosis with visual impairment. She underwent mini-facelift, upper blepharoplasty, dermabrasion and Minitac ${ }^{\circledR}$ brow suspension in May 2012. Two months later an excellent result has been maintained.

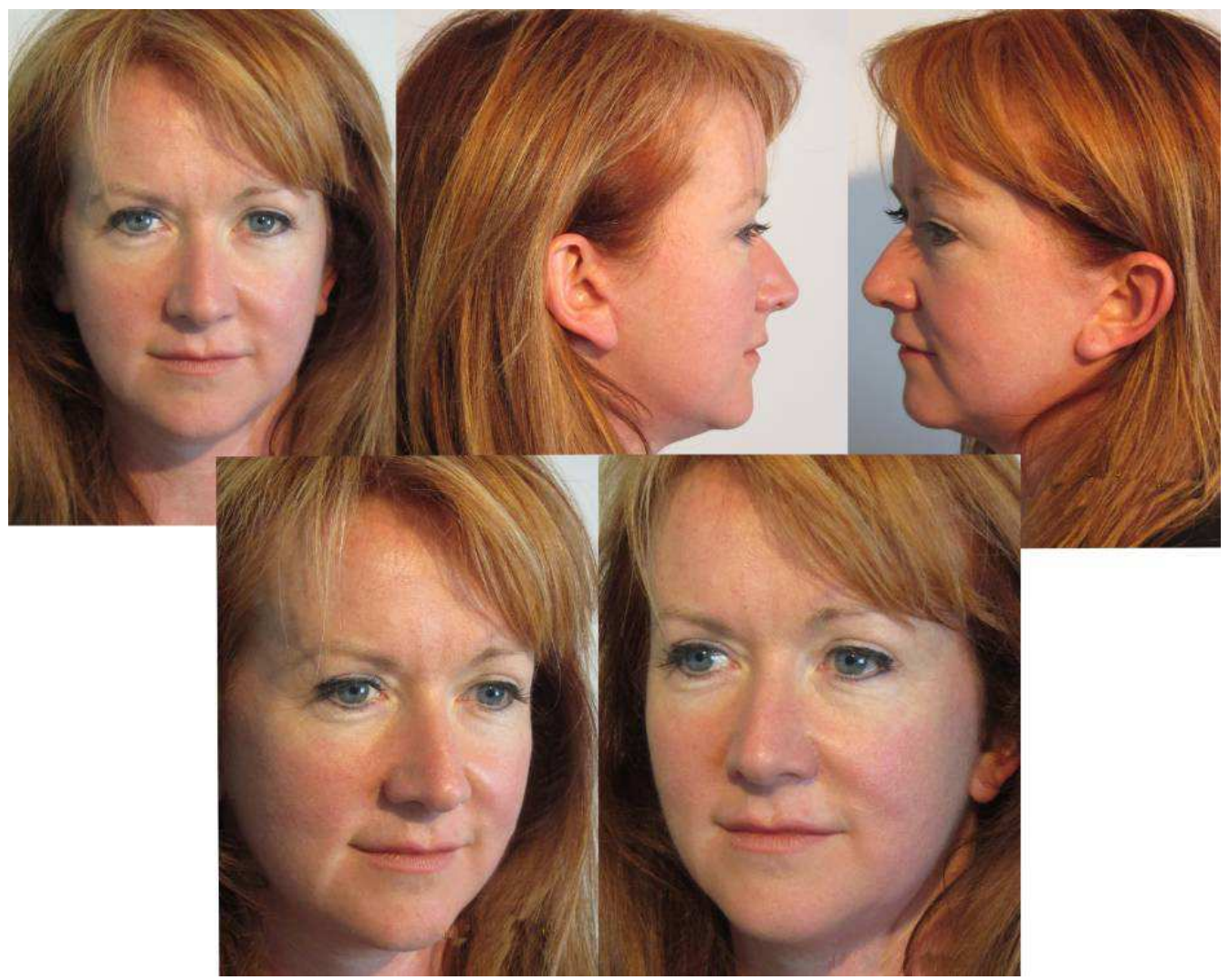

Figure 4. Ten weeks Postoperative photos showing significant improvement in brow ptosis and symmetry with no horizontal creases or visual evidence of surgery. 
Brow-lifting can be performed through well known open or closed methods, however in both situations the new brow position has to be maintained to allow healing and reattachment of the periosteum at the higher required position $(7,11)$. Various methods of fixation have been thoroughly reviewed in the literature (11). There is not a single best method of fixation, as each one has its advantages and disadvantages. Factors determining the choice of the fixation method include the length of time the fixation can be maintained, the amount of metal work or foreign body inserted, the extent of incisions and dissection, associated morbidity and complications, the technical difficulty of the technique, and the cost. Theoretically the best fixation method is one that can maintain the new higher brow position long enough for periosteal reattachment to occur (at least 6 weeks) $(12,13)$, yet does not remain beyond its purpose, is small in size, can be inserted through small incisions and involve minimal dissection. Finally, the fixation and elevation of the brow should be easy to perform and cheap.

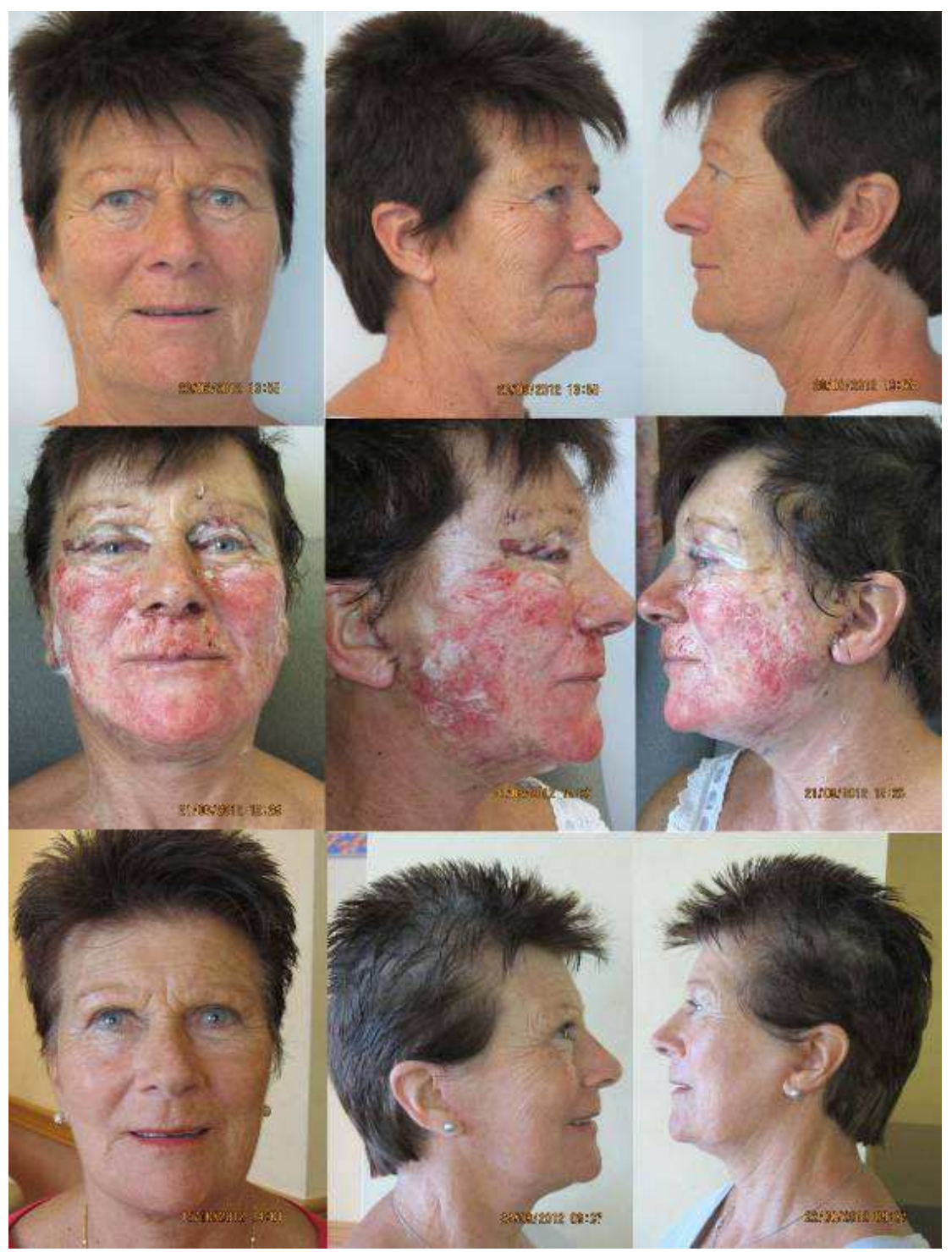

Figure 5. Mini-facelift, upper blepharoplasty, dermabrasion and Minitac ® brow suspension. Results of suture suspension of brow are maintained at 2 months.

Suture suspension techniques of the brow proved to be superior to other methods of fixation in many ways. Unlike Endotine ${ }^{2}$, the Mitek (Mitek Surgical Products, Westwood, Mass.) fixation device provides direct forehead lift, with a greater versatility in adjusting the vectors of brow lift, using a smaller size anchoring screw barely palpable under the skin (11). More recently screw devices were introduced with the apparent advantage of being made of absorbable material, therefore avoiding introduction of permanent metallic material $(10,14)$. Although some absorbable sutures can remain in the tissues as long as 7-8 months they will lose at least $40-65 \%$ of their tensile power before 6 weeks. Consequently we believe that permanent suture fixation would be more reliable to ensure long term maintenance of brow elevation. This was demonstrated by Romo et al. in his study showing that after a relatively long term follow up (18 
months), patients with temporary fixation techniques were more likely to have partial loss of brow elevation compared to those with permanent fixation techniques (15). A key advantage of the Minitac $\AA$ fixation device over other suture suspension devices is having two sutures attached to the single anchoring screw and the loop wire suture retrieval device. By placing the sutures correctly and anchoring into medial and lateral brow, there is a control to the vector of elevation of the medial and lateral brow using a single suture.

Suture suspension of the brow to a single fixed screw within the hairline of the forehead, has advantages over the Mitek® fixation device. Essentially, the Minitac ${ }^{\circledR}$ technique differentially elevates the medial and lateral ptotic brow and is secured using single screw fixation with one small incision in the scalp. The Endotine $\AA$ is more suitable for elevating the forehead rather than specifically elevating the eyebrows and if the brow elevation from Minitac ${ }^{\circledR}$ is excessive and fixed creases become more obvious, Endotine ${ }^{\circledR}$ could improve upon this. The two devices therefore may be complimentary.

\section{Conclusion}

The Minitac ${ }^{\circledR}$ suture device has proven to be a simple and effective method of suspension / fixation of the ptotic brow. It is easily handled and easily applied via minimal incisions, providing a controlled brow lift with a reliable permanent fixation ensuring long term maintenance of brow elevation. Having two sutures attached to one anchoring screw enables lifting both medial and lateral brow with a single device. Although made of permanent material, both the screw and the suture were not palpable under the skin. There were no complications and there was high patient satisfaction.

Minitac ${ }^{\circledR}$ is yet another tool that is translational from tendon and ligament fixation to Aesthetic Surgery.

\section{Acknowledgement}

Mr James D Frame (Jnr.) Research Assistant, Anglia Ruskin University, CM1 1SQ

\section{References}

[1] Lee CJ, Kim SG, Han JY. The results of periorbital rejuvenation with botulinum toxin A using two different protocols. Aesthetic Plast Surg 2006; 30/1:65-70.
[2] Graham DW, Heller J, Kirkjian TJ, Schaub TS, Rohrich RJ. Brow lift in facial rejuvenation: A systematic literature review of open versus endoscopic techniques. Plast Reconstr Surg 2001; 128: 335-341.

[3] Har-Shai Y, Gil T, Metanes I, ScheflanM. Brow lift of the correction of visual field impairment. Aesthet Surg J. 2008; 28/5:512-517.

[4] Elkwood A, Matarasso A, Rankin M, Elkowitz M, Godek CP. National Plastic Surgery Survey: Brow lifting techniques and complications. Plast Reconstr Surg 2001; 108:2143-2150.

[5] Dayan SH, Perkins SW, Vartanian AJ, Wiesman IM. The forehead lift: Endoscopic versus coronal approach. Aesthetic Plast Surg 2001; 25:35-39.

[6] Pascali M, Gualdi A, Bottini C, Botti G, Cervelli V. An original application of the endotine ribbon device for brow lift. Plast Reconstr Surg 2009; 124: 1652.

[7] Fiala TG, Owsley JQ. Use of the Mitek fixation device in endoscopic brow lifting. Plast Reconstr Surg 1998; 101/6: 1700-1703.

[8] Foustanos A, Zafrides H. An alternative fixation technique for the endoscopic brow Lift. Ann Plast Surg 2006; 56: 599-604.

[9] Mckinney P, Sweis I. An accurate technique for fixation in endoscopic brow lift: A 5 year follow-up. Plast Reconstr Surg 2001; 108:1808-1810.

[10] Landecker A, Buck J, Grotting J. A New resorbable tack fixation technique for endoscopic brow lifts. Plast. Reconstr. Surg 2003; 111:880-886.

[11] Rohrich RJ, Beran SJ. Evolving fixation methods in endoscopically assisted forehead rejuvenation: controversies and rationale. Plast Reconstr Surg 1997; 100:1575-1582.

[12] Romo T, Sclafani AP, Yung RT, McCormick SA, Cocker R, McCormick SU. Endoscopic foreheadplasty : A histologic comparison of periosteal refixation after endoscopic versus bicoronal lift. Plast Reconstr Surg 2000;105: 1111-1117.

[13] Jones B, Grover R. endoscopic brow lift: A personal review of 538 patients and comparison of fixation techniques. Plast Reconstr Surg 2004; 113: 1242-1250.

[14] Dorner BK, Owsley JQ. Update on Mitek endoscopic brow fixation system. Plast Reconstr Surg 2004; 113/2:735-736.

[15] Romo T, Sclafani AP, Yung RT. Endoscopic foreheadplasty: Temporary vs. permanent fixation. Aesth Plast Surg 1999; 23:388-394. 